ఠ

Open Access Full Text Article

REVIEW

\title{
An update on the treatment of type I and type 2 diabetes mellitus: focus on insulin detemir, a long-acting human insulin analog
}

This article was published in the following Dove Press journal:

Vascular Health and Risk Management

22 May 2010

Number of times this article has been viewed

\author{
Katarina Raslova \\ Metabolic Center Ltd and Slovak \\ Medical University, Bratislava, \\ Slovak Republic
}

\begin{abstract}
Basal insulin analogs are used to minimize unpredictable processes of NPH insulin. Modification of the human insulin molecule results in a slower distribution to peripheral target tissues, a longer duration of action with stable concentrations and thus a lower rate of hypoglycemia. Insulin detemir is a basal insulin analog that provides effective therapeutic options for patients with type 1 and type 2 diabetes. For glycemic control, no significant differences were found in $\mathrm{HbA}_{1 \mathrm{c}}$ levels compared with $\mathrm{NPH}$ and insulin glargine. It is comparable with insulin glargine in significantly reducing rates of all types of hypoglycemia. Clinical studies have demonstrated that detemir is responsible for significantly lower within-subject variability and no or less weight gain than NPH insulin and glargine. Recent pharmacodynamic studies have shown that detemir can be used once daily in many patients with diabetes. Together with patient-friendly injection devices and dose adjustments, it provides a treatment option with the potential to lower the key barriers of adherence to insulin therapy in type 2 diabetes. Recent guidelines for treatment of type 2 diabetes suggest starting intensive therapy of hyperglycemia at an early stage of diabetes and recommend therapeutic options that provide the possibility of reaching $\mathrm{HbA}_{1 \mathrm{c}}$ goals individually, with a low risk of hypoglycemia or other adverse effects of treatment. The properties of insulin detemir match these requirements.
\end{abstract}

Keywords: insulin analog, insulin detemir, diabetes mellitus, hypoglycemia, within-subject variability

\section{Introduction}

Diabetes mellitus (DM) is defined by the American Diabetes Association Expert Committee as a group of metabolic diseases characterized by hyperglycemia resulting from defects in insulin secretion, insulin action, or both. Chronic hyperglycemia is associated with long-term damage, dysfunction and failure of various organs, especially the eyes, kidney, nerves, heart and blood vessels. ${ }^{1}$

Type 1 diabetes mellitus (type $1 \mathrm{DM}$ ) is caused by absolute insulin deficiency resulting from autoimmune destruction of pancreatic B-cells. The autoimmune insulitis is characterized by a presence of auto-reactive T-lymphocytes and auto-antibodies against the antigen structures of B-cells. An approximate population incidence of type $1 \mathrm{DM}$ is $25 / 100,000$ with the highest incidence at the age of 13 to $15 .^{2}$ However, significant ethnic differences have been found, with the lowest incidence in China and Japan $(0.4 \text { and 1.6/100 000, respectively })^{1}$ and the highest in Finland $(40 / 100,000){ }^{3}$ For the etiopathology of type $1 \mathrm{DM}$, the substitution of missing insulin represents the only therapeutic option. Since publication of the DCCT trial, most of the patients with type $1 \mathrm{DM}$ are treated using an intensified regimen of basal-bolus therapy. ${ }^{4}$
Correspondence: Katarina Raslova Metabolic Center Ltd, Dumbierska 32, 83I 0 I Bratislava, Slovakia $\mathrm{Tel}+42$ I $25479 \mid 256$ Fax +42I 254791261

Email katarina.raslova@nextra.sk 
Type 2 diabetes mellitus (type $2 \mathrm{DM}$ ) is a heterogenous metabolic disorder characterized by a relative insulin deficiency resulting from a reduced sensitivity of tissues to insulin and impairment of insulin secretion from pancreatic B-cells. Some patients are characterized by predominant insulin resistance and relative insulin insufficiency, while the others have a major defect in insulin secretion combined with insulin resistance. Type 2 DM represents more than $80 \%$ of the DM cases. The prevalence of type $2 \mathrm{DM}$ is growing much more than has been previously estimated, in particular due to the increasing prevalence of obesity. It has been documented that earlier initiation of insulin therapy in type $2 \mathrm{DM}$, before the development of severe comorbidities, is required for improvement of metabolic control and prevention of microvascular and macrovascular complications. ${ }^{5} \mathrm{~A}$ therapeutic approach of earlier insulin initiation may have a role in the protection of B-cells from functional impairment due to long-term influence of hyperglycemia. ${ }^{6}$ Addition of insulin to oral anti-diabetic therapy (OAD) has been traditionally started with basal NPH (neutral protamine Hagedorn) insulin.

Until the recent introduction of basal insulin analogs, NPH insulin has been the most frequently used basal insulin, usually administrated in the evening. It is characterized by peaks in plasma insulin concentrations 5 to 10 hours after administration, increased risk of hypoglycemia during the night, and a duration of action of approximately 12 to 18 hours that may contribute to hyperglycemia in the morning. Common differences in crystal size and inadequate resuspension make absorption kinetics and dosing precision with NPH insulin variable and result in unpredictable glucose levels. ${ }^{7}$

Therefore, it was important to develop new basal insulins to minimize these concerns. The introduction of basal insulin analogs has resulted in a series of clinical trials that provide information on the most effective way of using these insulins in the treatment of type 1 and $2 \mathrm{DM}^{8}{ }^{8}$ The aim of this paper is to review new data on insulin detemir since the previous publication on this subject in this journal. ${ }^{9}$

\section{Pharmacokinetics}

Insulin detemir is a soluble derivative of human insulin (LysB29(N-tetradecanoyl) des (B30) human insulin), in which the threonine residue at position $\mathrm{B} 30$ of the human insulin molecule has been removed and a 14-carbon fatty acid side-chain has been attached to position B29. It has been demonstrated that insulin detemir has a faster dissociation from the insulin receptor and, thus, a lower molar potency than human insulin. This is why insulin detemir is formulated at a 4-fold higher molar concentration than human insulin. The protracted action of insulin detemir is mediated by the strong self-association of insulin detemir hexameric molecules at the injection site and albumin binding via the myristic fatty acid side-chain. The rate of absorption is limited by the low concentration of insulin detemir available for diffusion through the tissue and passage across the capillary wall. The fatty acid, myristic acid, enables insulin detemir to bind to albumin in the subcutaneous tissue and interstitium. More than $98 \%$ of insulin detemir in the bloodstream is albumin bound, which makes detemir more slowly distributed to peripheral target tissues compared to NPH insulin. ${ }^{10}$ The addition of the fatty acid also allows insulin detemir to be formulated as a solute in a neutral liquid solution, which does not precipitate during administration or absorption. This stable, soluble profile of insulin detemir contrasts with that of insulin glargine which precipitates from its acidic solution in the neutral subcutaneous tissues after injection. ${ }^{11}$ Because precipitation and dissolution of a precipitate are unpredictable processes, the mechanism of protracted absorption of insulin detemir may contribute to reduced variability in insulin detemir action.

These pharmacological properties have been suggested to be responsible for significantly lower within-subject variability than NPH and insulin glargine, which has been demonstrated in clamp studies of type 1 DM across all age groups. ${ }^{12-14}$

The examination of time-action profiles and the doseresponse relationship of detemir and NPH insulin in African Americans, Hispanic/Latinos and Caucasians with type $2 \mathrm{DM}$ was done using a double-blind crossover trial. ${ }^{15}$ Each patient took part in six 16-hour isoglycemic glucose clamps (clamp target $7.2 \mathrm{mmol} / \mathrm{L}$ ) and was randomly allocated to 3 doses $(0.3,0.6$ and $1.2 \mathrm{IU} / \mathrm{kg})$ of detemir and NPH, respectively. Comparable results were obtained for pharmacokinetics for all the ethnic groups. These results suggest that similar dosing recommendations can be used for detemir in type $2 \mathrm{DM}$ patients belonging to different ethnic groups.

\section{Pharmacodynamics}

Insulin detemir was originally licensed for once- or twicedaily administration. A pharmacodynamic clamp study in type $1 \mathrm{DM}$ comparing detemir with NPH insulin has shown that insulin detemir at a dose of $0.4 \mathrm{IU} / \mathrm{kg}$ had an average duration of action of 20 hours, which was significantly longer than that of NPH insulin. ${ }^{16}$

The repeat-clamp study that compared the pharmacodynamic profile of the two basal analogs and NPH insulin in type $1 \mathrm{DM}$ had, as its primary objective, the examination of within-subject variability. ${ }^{13}$ This study has shown signifi- 
cantly lower within-subject variability of insulin detemir than that of the comparators. The continued duration of action at 24 hours of studied insulins was 14\% for NPH insulin, 24\% for insulin detemir and 39\% for glargine. Porcellati et $\mathrm{al}^{17}$ compared the pharmacodynamics of basal insulin analogs in 24 patients with type $1 \mathrm{DM}$ after a 2-week treatment with either glargine or detemir once daily in a randomized, doubleblind, crossover study. Glucose infusion rate was similar with detemir and glargine for the first 12 hours. However, plasma glucose increased progressively after 16 hours with detemir demonstrating a lower effect than insulin glargine during the period of 12 to 24 hours.

In another randomized, double-blind trial with 3 euglycemic glucose clamp experiments, 27 insulin-treated patients were examined. They received $0.4,0.8$ and $1.4 \mathrm{IU} / \mathrm{kg}$ of either insulin detemir or glargine. The duration of action was comparable between the two analogs and it increased with a rise in the doses. Within-subject variability was lower for detemir, and between-subject variability did not differ between treatments. ${ }^{18}$ Recently, a double-blind, randomized, crossover study in patients with type 2 DM examined the glucose-lowering effect of detemir and glargine, using an assessment of continuous glucose monitoring. Over a 24-hour period, once-daily dosing with insulin detemir provided a similar glycemic control to that of insulin glargine after both had been titrated to the same glucose target. ${ }^{19}$

Despite a lower rate of hypoglycemia in patients treated with basal insulin analogs, it is important to study symptom awareness of either insulin treatment. Hormone and symptom response in healthy subjects was tested during a hypoglycemic clamp with insulin detemir and human insulin in random order. ${ }^{20}$ Insulin detemir increased symptom awareness during hypoglycemia (sweating, especially, was earlier and faster) compared to human insulin in healthy individuals, whereas counter-regulatory hormone response and cognitive function were unaltered.

\section{Detemir in pregnancy}

Until now, there are no clinical studies or reports on the use of insulin detemir in pregnant women with diabetes. However, clinical studies are ongoing. Animal reproduction studies in rabbits and rats revealed no significant differences between insulin detemir and human insulin for embryotoxicity and teratogenicity. ${ }^{21}$

\section{Efficacy and safety in type I DM}

The initial studies in type $1 \mathrm{DM}$ compared effects on glucose metabolic parameters and the safety profile of a twice-daily insulin detemir administration with NPH insulin. These studies used a basal-bolus regimen, and were randomized and open-label, since the insulin detemir is injected as a solution and NPH insulin as a suspension. Their duration was at least 20 weeks. Most of these studies have shown a favorable effect of insulin detemir on body weight compared to NPH insulin.

Singh et $\mathrm{al}^{22}$ published a meta-analysis of randomized controlled trials which reported data and comparisons in patients with type 1 and type $2 \mathrm{DM}$ treated with insulin analogs versus regular human insulin or one long-acting insulin analog versus another. Results on hemoglobin $\mathrm{HbA}_{10}$ $\left(\mathrm{HbA}_{1 \mathrm{c}}\right)$, hypoglycemia, quality of life, complications and adverse effects were presented. The authors did not focus on such outcomes as fasting plasma glucose, 2-hour postprandial glucose, body weight, plasma lipids or blood pressure. The precise methodology of data extraction analysis was described. In a pooled analysis of 7 trials comparing insulin detemir and NPH insulin in 2558 type $1 \mathrm{DM}$ adult patients, no significant differences in $\mathrm{HbA}_{1 \mathrm{c}}$ were found, but statistically significant reductions in the risk of severe hypoglycemia (relative risk [RR] 0.74, 95\% confidence interval [CI] 0.58 to 0.96 ) and nocturnal hypoglycemia (RR $0.92,95 \%$ CI 0.85 to 0.98 ) were demonstrated.

Recent randomized studies examined the efficacy and safety of once- and twice-daily detemir in comparison with NPH or insulin glargine (Table 1). Insulin glargine and insulin detemir, each compared with NPH insulin, were examined by Pieber et $\mathrm{al}^{23}$ to study glycemic control and risk of hypoglycemia of twice-daily insulin detemir with oncedaily insulin glargine in 320 subjects with type $1 \mathrm{DM}$. The treatment did not show any significant differences in body weight gain between insulin detemir and insulin glargine, or a difference in $\mathrm{HbA}_{1 \mathrm{c}}$. But the risk of severe hypoglycemia (RR $0.25,95 \%$ CI 0.07 to 0.86 ) and the rate ratios for severe and nocturnal hypoglycemia were statistically significantly lower in favor of insulin detemir.

A trial comparing insulin detemir versus NPH insulin in children and adolescents with type $1 \mathrm{DM},{ }^{24}$ did not show any differences in $\mathrm{HbA}_{1 \mathrm{c}}$ or frequency of severe hypoglycemia. However, benefits in favor of insulin detemir were found in a lower risk of nocturnal hypoglycemia. In this study, lower and more predictable fasting plasma glucose and lower body mass index were also advantages of the treatment with insulin detemir.

Recent studies have suggested ${ }^{25}$ that insulin detemir has a pharmacodynamic profile which allows its administration once daily. The treat-to-target ADAPT study ${ }^{26}$ examined 
Table I Recent randomized trials in type I diabetes mellitus

\begin{tabular}{ll}
\hline Study & Therapy and objectives \\
\hline Pieber et al $^{23}$ & Comparison of glycemic control and risk of \\
$\mathrm{N}=320$ & hypoglycemia of twice-daily insulin detemir \\
26 -week & with once-daily insulin glargine \\
Randomized, multicenter, open-label, & \\
parallel-group &
\end{tabular}

Robertson et $\mathrm{al}^{24}$

$\mathrm{N}=347$ children

26-week

Randomized (2:I), multicenter,

open-label, parallel-group
Efficacy and safety of detemir vs NPH. Once- or twice-daily according to the pre-study regimen, plus premeal insulin aspart
Bartley et $\mathrm{al}^{28}$

$\mathrm{N}=497$

24-month

Randomized(2:I), multicenter,

open-label, parallel-group, treat-to-target

Le Floch et $\mathrm{a}^{26}$

$\mathrm{N}=520$

7-month

Randomized, multicenter,

open-label, treat-to-target

Heller et $\mathrm{al}^{27}$

$\mathrm{N}=443$

52-week

Randomized (2:I), multicenter,

open-label, treat-to-target non-inferiority
Long-term efficacy and safety of detemir vs $\mathrm{NPH}$, plus premeal insulin aspart. Basal insulin initiated once daily, titrated based on PG levels, aiming for pre-breakfast and pre-dinner targets $\leq 6.0 \mathrm{mmol} / \mathrm{L}$

Comparison of the efficacy and safety of once- and twice-daily detemir, plus premeal insulin aspart. After 4-month therapy twice-daily switched to once-daily

Comparison of detemir with glargine, plus premeal insulin aspart. Detemir initiated once daily, titrated based on PG levels, if not achieved the pre-dinner targets patients switched to twice-daily detemir

Abbreviations: Det, detemir; Glar, glargine; Det once, detemir once-daily; Det twice, detemir twice-daily; FPG, fasting plasma glucose; noctur, nocturnal; NPH, neutral protamine Hagedorn; ns, not significant; PG, plasma glucose; SD, standard deviation.

effects of insulin detemir in a basal-bolus insulin regimen in 520 patients with type $1 \mathrm{DM}$ who were randomly assigned to receive detemir once or twice daily with insulin aspart. Insulin doses were titrated over 1 month. After 3 months of follow-up, a majority of patients continued with a twice-daily regimen, with an additional 3-month follow-up. The authors found that the most suitable routine starting schedule for detemir in a basal-bolus regimen for type 1 DM was oncedaily injection.
Another study had a primary objective to determine whether insulin detemir was non-inferior to insulin glargine in a basal-bolus regimen, with insulin aspart as the mealtime insulin, in terms of glycemic control in 443 patients with type $1 \mathrm{DM}^{27}$ At this multinational, open-label, parallel-group, treat-to-target, non-inferiority trial the patients were randomized in a $2: 1$ ratio to receive either detemir or glargine for 52 weeks. The basal insulin was initially administered once daily in the evening in both 
groups; if patients in the detemir group were achieving the plasma glucose target before breakfast but not before dinner, they were switched to twice-daily administration. Glargine was administered once daily throughout the trial, according to its approved labeling. At the end of the study $\mathrm{HbA}_{1 \mathrm{c}}$ levels, rates of hypoglycemia, estimated mean fasting plasma glucose (FPG) or insulin doses did not differ significantly between the detemir and glargine groups. Approximately one third of the patients with detemir completed the trial on once-daily and the rest of them on twice-daily administration. The basal insulin dose was higher in patients receiving detemir twice rather than once daily ( $0.47 \mathrm{vs} 0.33 \mathrm{IU} / \mathrm{kg}$, respectively).

The long-term efficacy and safety of insulin detemir compared to NPH insulin was examined in a 2-year, randomized, controlled trial in patients with type $1 \mathrm{DM}$ using a treat-to-target basal-bolus regimen with insulin aspart. ${ }^{28}$ In this study, $22 \%$ of patients treated with insulin detemir reached a $\mathrm{HbA}_{1 \mathrm{c}} \leq 7.0 \%$ in the absence of confirmed hypoglycemia during the last month of treatment vs $13 \%$ on NPH insulin $(P=0.02)$. Detemir was associated with a $69 \%$ lower risk of major hypoglycemic episodes compared to NPH $(P<0.001)$. The risk of nocturnal hypoglycemia was $46 \%$ lower with detemir than with NPH $(P<0.001)$. Moreover, patients treated with detemir gained less weight (detemir $1.7 \mathrm{~kg}$, NPH $2.7 \mathrm{~kg} ; P=0.02$ ).

A large, multi-national, prospective, observational study PREDICTIVE ${ }^{29}$ evaluated the safety and efficacy of insulin detemir in patients with diabetes in daily practice. The European cohort included 20,531 patients. A subgroup of 4782 type $1 \mathrm{DM}$ patients was transferred from a basal-bolus regimen with NPH insulin $(\mathrm{n}=3117)$ or insulin glargine $(n=1665)$ to insulin detemir basal-bolus therapy; or from a human insulin basal-bolus regimen $(n=570)$ to insulin detemir/insulin aspart. After mean follow-up of 14.4 weeks $\mathrm{HbA}_{1 \mathrm{c}}$ and hypoglycemia were reduced by $0.6 \%$ and $54 \%$ $(P<0.0001$, respectively) with weight neutrality. Mean fasting glucose and within-patient fasting glucose variability significantly decreased in all patients $(P<0.0001)$.

\section{Efficacy and safety in type 2 DM}

A clinical situation during the development of type $2 \mathrm{DM}$ is that it might be inadequately controlled by OADs. A typical response is to intensify the therapeutic regimen. Intensive treatment of patients with type $2 \mathrm{DM}$ is in line both with the consensus algorithm and the guidelines. ${ }^{30}$

In 2007, a Cochrane database analysis was published that evaluated advantages of the treatment with basal insulin analogs in comparison with NPH insulin in type 2 DM. Six studies with insulin glargine and two studies with detemir were analyzed. Their duration was from 24 to 54 weeks. No differences between basal insulin analogs and NPH insulin in $\mathrm{HbA}_{1 \mathrm{c}}$ have been shown; however, a significantly lower rate of symptomatic, overall and nocturnal hypoglycemia were found in favor of basal insulin analogs. ${ }^{31}$ This review concluded: "For insulin therapy in diabetes mellitus, NPH is an effective, safe substance which has been tested over decades. In such cases where a proven effective therapy is available, the introduction of new substances should only be advised if there is a major improvement in efficacy, or if the new substance is proven both effective and safe".

In the meantime, from this Cochrane analysis new data on the significance of hypoglycemia for the risk of fatal cardiovascular complications in patients with type $2 \mathrm{DM}$ were published. ${ }^{32}$ For these novel findings, the importance of lowering the risk of hypoglycemia has become a major issue of the treatment. This was also reflected in a recent Consensus Statement of the American Association of Clinical Endocrinologists/American College of Endocrinology. The authors of this document recommend achieving an $\mathrm{HbA}_{1 \mathrm{c}}$ of $6.5 \%$ as the primary goal of the treatment of type $2 \mathrm{DM}^{33}$ A novel statement of this panel is to use the basal synthetic analogs, insulin glargine and insulin detemir, instead of NPH insulin because the basal analogs provide a relatively peakless profile for approximately 24 hours and yield better reproducibility and consistency, both between patients and within patients, and a corresponding reduction in the risk of hypoglycemia.

First were two studies with insulin detemir in type 2 DM with a similar design. They were multinational, open-label, randomized, parallel group trials comparing efficacy and safety of basal-bolus therapy using either insulin detemir in combination with meal-time insulin aspart versus NPH insulin in combination with meal-time regular human insulin ${ }^{34}$ or basal-bolus insulin regimen comprising either insulin detemir or NPH insulin both in combination with mealtime insulin aspart. ${ }^{35}$ Patients received basal insulin either once or twice daily according to their pretrial insulin treatment and insulin aspart or regular insulin at mealtimes. In the first study, ${ }^{34}$ a 22 -week long therapy of 395 people with type $2 \mathrm{DM}$ resulted in comparable $\mathrm{HbA}_{1 \mathrm{c}}$ between treatments, with decreases from their baselines of $0.65 \%$ and $0.58 \%$ in the detemir and the NPH group, respectively. Treatment with insulin detemir + aspart was associated with a significantly lower within-person 
variation in self-measured FPG, as well as a lower body weight gain than that of NPH plus regular insulin $(0.51$ versus $1.13 \mathrm{~kg}, P=0.038$ ). The relative risk of nocturnal hypoglycemia was significantly lower in the detemir group (RR $0.54,95 \%$ CI 0.30 to $0.97 ; P<0.04$ ).

In a second study, ${ }^{35}$ a 26 -week long therapy of 505 patients resulted in comparable glycemic control but significantly lower within-subject variability and less weight gain in the detemir group compared to patients treated with $\mathrm{NPH}$ insulin (1.0 and $1.8 \mathrm{~kg}$, respectively, $P=0.017$ ). Insulin detemir was well tolerated and had a similar safety profile to NPH insulin.

Efficacy and tolerability of insulin detemir or NPH insulin added to oral therapy for type $2 \mathrm{DM}$ was examined in a treat-to-target titration protocol. ${ }^{36}$ In a parallel-group, multicenter trial, 476 patients with high levels of $\mathrm{HbA}_{1 \mathrm{c}}$ were randomized to addition of twice-daily insulin detemir or NPH insulin. Over 24 weeks, insulin doses were titrated toward pre-breakfast and pre-dinner plasma glucose targets of $\leq 6.0 \mathrm{mmol} / \mathrm{L}$. This resulted in comparable reductions of $\mathrm{HbA}_{1 \mathrm{c}}$ for detemir and NPH (from 8.6 to 6.8 and from 8.5 to $6.6 \%$, respectively). Compared with NPH insulin, in patients treated with insulin detemir the risk for all and for nocturnal hypoglycemia was reduced by $47 \%$ and $55 \%$, respectively $(P<0.001)$. They profited as well from significantly lower weight gain.

Another trial examined the effect of an evening detemir, a pre-breakfast detemir, or an evening NPH insulin administered at initial doses of $10 \mathrm{IU}$ in 498 patients treated with $\geq 1$ OAD. $^{37}$ Similar reductions of $\mathrm{HbA}_{1 \mathrm{c}}$ of all three regimens were found after titration of administered insulins. All-day and nocturnal hypoglycemia were reduced significantly with morning and evening detemir. Nocturnal hypoglycemia was reduced further, by $87 \%$, with morning detemir compared with evening NPH $(P<0.001)$. Less weight gain was observed for evening detemir vs NPH $(P=0.005)$.

In a 26-week multinational, multicenter, randomized treatto-target trial, OADs were discontinued and subjects were randomized to analog basal-bolus therapy (insulin detemir once daily and insulin aspart at mealtimes) or biphasic insulin aspart 30 , twice daily. ${ }^{38}$ Both insulin analog regimens enabled a majority of people with type $2 \mathrm{DM}$ to reach $\mathrm{HbA}_{1 \mathrm{c}} \leq 7.0 \%$ after the failure of OADs and OAD-basal insulin therapy. Insulin-treated patients had more benefit from the transfer to analog basal-bolus therapy, while insulin-naive individuals had more benefit from the biphasic analog regimen.

Insulin detemir was compared with insulin glargine in the following randomized controlled trials (Table 2):
1. The study by Hollander et $a l^{39}$ was one of the first to directly compare the efficacy of detemir with glargine in a basal-bolus regimen in patients with type 2 diabetes. It was a multinational, 52-week, open label, parallel-group, non-inferiority, treat-to-target trial. Type $2 \mathrm{DM}$ patients who had been receiving an OAD or insulin (with or without OADs) were randomized in a 2:1 ratio to receive insulin detemir or glargine. Detemir could be administered once or twice daily, glargine was administered once daily. Insulin aspart was given at mealtimes. Insulin secretagogs and $\alpha$-glucosidase inhibitors were discontinued at study entry, but other existing OADs were continued. Doses of detemir and glargine were titrated to achieve a pre-breakfast (and pre-dinner for detemir administered twice daily) plasma glucose target of $\leq 6.0 \mathrm{mmol} / \mathrm{L}$. At 52 weeks, decreases of $\mathrm{HbA}_{1 \mathrm{c}}$ from baseline for detemir and glargine were similar at $-1.52 \%$ and $-1.68 \%$, respectively. The proportion of detemir-treated subjects who achieved an $\mathrm{HbA}_{1 \mathrm{c}} \leq 7 \%$ was $36.2 \%$, compared with $36.7 \%$ of glargine-treated subjects. $82.7 \%$ of the detemir-treated subjects and $83.8 \%$ of the glargine-treated subjects failed to achieve pre-supper glucose levels of $\leq 6.0 \mathrm{mmol} / \mathrm{L}$. Both insulin analogs were well tolerated, with no significant difference in the frequency of hypoglycemia. However, mean weight gain was significantly lower with detemir than with glargine (2.8 vs $3.8 \mathrm{~kg}, 95 \% \mathrm{CI}-2.08$ to $-0.01 ; P<0.05)$. Overall, the detemir-treated subjects used more insulin than the glargine-treated subjects (0.82 units $/ \mathrm{kg}$ vs 0.69 units $/ \mathrm{kg}$, respectively), but this difference disappearred when comparing only single-dose detemir-treated subjects who used an average daily basal insulin dose of 0.69 units $/ \mathrm{kg}$.

2. A second trial also had a 52 -week duration. ${ }^{40}$ This study was multinational, randomized, open-label, parallel-group and non-inferiority. The aim was to examine clinical outcomes following supplementation of OADs with basal insulin analogs detemir or glargine in 582 insulin-naive type $2 \mathrm{DM}$ patients. Insulin doses were in the evening titrated to target fasting plasma glucose $\leq 6.0 \mathrm{mmol} / \mathrm{L}$. An additional morning insulin detemir dose was permitted if pre-dinner FPG was $>7.0 \mathrm{mmol} / \mathrm{L}$ after achieving FPG $<7.0 \mathrm{mmol} / \mathrm{L}$. $\mathrm{HbA}_{1 \mathrm{c}}$ and FPG decreased comparrably with detemir and glargine. $45 \%$ of participants treated with insulin detemir completed the study on once daily dosing and $55 \%$ of them completed on twice daily dosing, with no difference in $\mathrm{HbA}_{1 \mathrm{c}}$. Overall, $52 \%$ of patients achieved $\mathrm{HbA}_{1 \mathrm{c}} \leq 7.0 \%: 33 \%$ (detemir) and $35 \%$ (glargine) without hypoglycemia. Within-patient 
Table 2 Randomized trials comparing insulin detemir and insulin glargine in type 2 diabetes mellitus (DM)

Study
Hollander et al $^{39}$
$\mathrm{~N}=319$
52-week randomized (2:I), multicenter,
open-label, parallel-group, noninferiority,
treat-to-target

Rosenstock et $\mathrm{al}^{40}$

$\mathrm{n}=582$

52-week randomized, multicenter, openlabel, treat-to-target

Raskin et $\mathrm{al}^{41}$

$\mathrm{N}=385$

26-week randomized (2:I), multicenter, open-label, parallel-group, noninferiority, treat-to-target

Swinnen et $\mathrm{al}^{42}$

$\mathrm{N}=973$

24-week randomized, multicenter, openlabel,

parallel-group, noninferiority, treat-to-target

Therapy and objectives

Comparison of Det and Glar added to type 2DM who had been receiving an OAD or insulin, with or without OADs. Det, QD (evening) or BID (morning + evening) or Glar, QD (evening), plus premeal insulin aspart Existing OADs were continued but insulin secretagogs and a-glucosidase inhibitors were discontinued

\author{
Comparison of Det and Glar added to OAD in \\ insulin-naive patients \\ Det, QD (evening) or BID (morning + evening) \\ or Glar, QD (evening). Initiate therapy at 12 \\ units, titrate to FPG target of $<6 \mathrm{mmol} / \mathrm{L}$
}

Comparison of the efficacy and safety of Det and Glar in a basal-bolus (premeal insulin aspart) regimen in type 2DM

\begin{abstract}
Comparison of percentage of patients reaching $\mathrm{HbA}_{\mathrm{Ic}}<7 \%$ without symptomatic hypoglycemia $\leq 3.1 \mathrm{mmol} / \mathrm{L}$ in insulin-naive type $2 \mathrm{DM}$ on stable OGLDs who were randomized to Glar once-daily or Det twice-daily
\end{abstract}

\author{
Summary of results \\ Det vs Glar, $P$ \\ $\mathrm{HbA}_{\mathrm{Ic}}-1.52 \%$ vs $-1.68 \%$, ns \\ Body weight $(\mathrm{kg})+2.8+3.8 .0 .05$ \\ Within-subject variability, ns. Overall \\ hypoglycemia, ns. Overall, the Det-treated \\ subjects used more insulin than the Glar- \\ treated subjects $(0.82 \mathrm{IUs} / \mathrm{kg}$ vs $0.59 \mathrm{IU} / \mathrm{kg}$, \\ respectively), but this difference disappeared \\ when comparing only single-dose Det-treated \\ subjects who used an average daily basal insulin \\ dose of $0.69 \mathrm{U} / \mathrm{kg}$ \\ Det vs Glar, $P$ \\ $\mathrm{HbA}_{\mathrm{lc}}-1.4 \%$ vs $-1.5 \%$, ns \\ Body weight $(\mathrm{kg})+3.0 \mathrm{vs}+3.9,0.01$ \\ Within-subject variability, ns \\ Overall hypoglycemia, ns \\ $45 \%$ of participants completed on once-daily \\ Det with mean daily dose of $0.52 \mathrm{lU} / \mathrm{kg}$ and $55 \%$ \\ of them on twice-daily with mean daily dose of \\ I.0 IU/kg. Mean daily dose of Glar was $0.44 \mathrm{lU} / \mathrm{kg}$ \\ Det vs Glar, $P$ \\ $\mathrm{HbA}_{\mathrm{lc}}-1.1 \% \mathrm{vs}-1.3 \%$, ns \\ Body weight $(\mathrm{kg})+1.2 \mathrm{vs}+2.7,0.01$ \\ Within-subject variability, ns \\ Overall hypoglycemia ns $87.4 \%$ of Det-treated \\ patients remained on a once-daily basal insulin \\ regimen at comparable basal insulin dosage. \\ Mean basal insulin doses were comparable \\ between treatments (Det $0.8 \mathrm{I}$ vs Glar $0.75 \mathrm{IU} / \mathrm{kg}$, \\ $P=0.1)$ \\ Det vs Glar, $P$ \\ $\mathrm{HbA}_{\mathrm{lc}}-1.54 \%$ vs $-1.46 \%$, ns \\ Body weight $(\mathrm{kg}) 0.6 \mathrm{vs} \quad 1.4,0.00$ I \\ Overall hypoglycemia ns $27.5 \%$ and $25.6 \%$ \\ of patients reached $\mathrm{HbA}_{\mathrm{lc}}<7 \%$ without \\ symptomatic hypoglycemia $\leq 3.1 \mathrm{mmol} / \mathrm{L}$. \\ More patients with Det reached $\mathrm{HbA} \mathrm{Ic}_{\mathrm{lc}}<6.5 \%$ \\ $(P=0.017)$. Glar doses were lower than Det \\ doses: 43.5 vs $76.5 \mathrm{IU} / \mathrm{d}(P<0.00 \mathrm{I})$
}

Abbreviations: Det, detemir; Glar P, glargine; Det once, detemir once-daily; Det twice, detemir twice-daily; FPG, fasting plasma glucose; ns, not significant; OAD, oral anti-diabetic therapy; OGLD, oral glucose-lowering drugs; QD, once daily; BID, twice daily.

variability for self-monitored FPG and pre-dinner plasma glucose did not differ by insulin treatment, nor did the relative risk of overall or nocturnal hypoglycemia. Modest differences in less weight gain were seen with detemir vs glargine in completers ( $3.0 \mathrm{vs} 3.9 \mathrm{~kg}, P=0.01)$. Mean daily detemir dose was higher $(0.78 \mathrm{IU} / \mathrm{kg}[0.52$ with once-daily dosing, $1.00 \mathrm{IU} / \mathrm{kg}$ with twice-daily dosing]) than glargine $(0.44 \mathrm{IU} / \mathrm{kg})$. Injection site reactions were more frequent with detemir (4.5 vs $1.4 \%$ ).

3. Another trial comparing the two basal insulin analogs had a treat-to-target design. ${ }^{41}$ This 26 -week study compared the efficacy and safety of insulin detemir and insulin glargine in a basal-bolus (insulin aspart) regimen in 385 type 2 DM patients who were randomized $2: 1$. Insulin detemir and glargine were both equally effective and safe treatments for glycemic control. $\mathrm{HbA}_{1 \mathrm{c}}$ decreased significantly from the baseline in detemir to $7.1 \%(-1.1 \%$, $P<0.001)$ and in glargine to $6,9 \%(-1.3 \%, P<0.001)$. There was significantly less weight gain in the detemir group at comparable basal insulin dosage (1.2 \pm 3.96 vs $2.7 \pm 3.94 \mathrm{~kg}, P=0.001 ; 95 \% \mathrm{CI}-2.19$ to -0.56$)$. At the end of this study, $87.4 \%$ of detemir-treated patients remained on a once-daily basal insulin regimen.

4. The aim of another trial was to determine whether glargine was non-inferior to detemir for the percentage of patients reaching $\mathrm{HbA}_{1 \mathrm{c}}<7 \%$ without symptomatic hypoglycemia $\leq 3.1 \mathrm{mmol} / \mathrm{L} .{ }^{42}$ This 24 -week trial examined 973 insulin-naive type 2 diabetes patients on stable 
OADs and $\mathrm{HbA}_{1 \mathrm{c}} 7.0 \%$ to $10.5 \%$, who were randomized to glargine once daily or detemir twice daily. Insulin doses were systematically titrated. A similar proportion of type $2 \mathrm{DM}$ patients reached the primary outcome with glargine and detemir, demonstrating the non-inferiority of glargine. However, more detemir-treated patients reached $\mathrm{HbA}_{1 \mathrm{c}}<6.5 \%(P=0.017)$, while hypoglycemia risk was similar. Weight gain was higher for glargine $(1.44 \pm 3.2$ and $0.6 \pm 2.9 \mathrm{~kg}$; difference: $0.77 \mathrm{~kg}, P<0.001)$ and glargine doses were lower than detemir doses: $43.5 \pm 29.0$ versus $76.5 \pm 50.5$ units/day $(P<0.001)$.

Effects of complex insulin regimens were examined in a 3-year open-label, multicenter trial that examined 708 patients taking metformin and sulfonylurea. These subjects were randomly assigned to receive biphasic insulin aspart twice daily, prandial insulin aspart 3 times daily, or basal insulin detemir once daily (twice if required). ${ }^{43}$ Sulfonylurea therapy was replaced by a second type of insulin if hyperglycemia became unacceptable during the first year of the study or subsequently if $\mathrm{HbA}_{1 \mathrm{c}}$ levels were more than $6.5 \%$. $\mathrm{HbA}_{1 \mathrm{c}}$ were similar for all regimens. A level of $6.5 \%$ or less was achieved in $31.9 \%$ of patients in the biphasic group, in $44.7 \%$ of patients in the prandial group $(P=0.006)$ and in $43.2 \%$ of patients in the basal group $(P=0.03)$. A second type of insulin was taken by $67.7 \%, 73.6 \%$, and $81.6 \%$ of patients, respectively $(P=0.002)$. Fewer hypoglycemic episodes and less weight gain occurred in patients adding basal insulin.

Predictable Results and Experience in Diabetes through Intensification and Control to Target: an International Variability Evaluation (PREDICTIVE) was a multi-national, open-label, prospective, observational study assessing the safety and efficacy of insulin detemir in clinical practice. A post-hoc analysis in type $2 \mathrm{DM}$ insulin-naïve patients has shown a benefit from adding a once-daily insulin detemir. ${ }^{44,45}$ Improvement of glycemic control was achieved, with good tolerability, including a low risk of hypoglycemia and a weight-sparing effect.

\section{Detemir and body weight}

Insulin-related weight gain can be detrimental to the patient with diabetes for a number of reasons ${ }^{46}$ The prospect of weight gain, coupled with concerns about hypoglycemia, can lead to reluctance or delay by healthcare professionals and patients in initiating or intensifying insulin therapy. Weight gain with insulin therapy has been shown to have potentially undesirable physiological effects, which include increased blood pressure, cholesterol and triglyceride levels, decreased high-density lipoprotein cholesterol and increased waist-to-hip ratio. ${ }^{47}$ As these changes are known to be associated with increased cardiovascular risk, it is possible that they will to some extent limit the prognostic benefits gained from improved glycemic control. Weight gain is also associated with deterioration in glycemic control, leading to an increase in insulin resistance. ${ }^{48}$ There is therefore a need to minimize weight gain with insulin therapy.

Until recently, many patients had little alternative other than to accept unwanted weight gain if they were to achieve sufficient glycemic control to reduce risk of chronic complications of diabetes. Insulin detemir has consistently been shown in randomized, controlled trials to have a weight-sparing effect in both type $1 \mathrm{DM},{ }^{49-55}$ and type $2 \mathrm{DM}^{36,56,57}$ This effect appears to be most prominent in people who are the most obese. The weight-sparing effects of insulin detemir have been consistently seen in randomized trials comparing the two basal insulin analogs in type $2 \mathrm{DM}$. Although insulin glargine has been shown to have an advantage of lower weight increase compared with NPH insulin in some studies, in most of these trials no difference between glargine and NPH insulin was demonstrated. ${ }^{58}$

The mechanisms behind the weight-sparing effect of insulin detemir are still being clarified. Reduced risk of hypoglycemia with insulin detemir, coupled with a more consistent and reliable delivery of desired dose than is available with traditional basal insulin, has been proposed to minimize defensive snacking by patients, and help to limit weight gain. However, reduced risk of hypoglycemia, which decreases defensive snacking by patients, is unlikely to fully explain the weight-sparing effect of insulin detemir. ${ }^{59}$ It has been suggested that due to prolonged action via acylation and albumin binding, insulin detemir may differentially influence hepatocytes more than peripheral tissues, thus effectively suppressing hepatic glucose output without promoting lipogenesis in the periphery. ${ }^{60}$

The second theory suggests that insulin detemir may be more effective than human insulin in communicating satiety signals within the central nervous system. This hypothesis of a direct effect of insulin detemir on the brain to reduce food intake was tested in healthy volunteers using the method of magnetoencephalography to examine the activity of the cerebral cortex in lean and overweight non-diabetes humans during a 2-step hyperinsulinemic euglycemic clamp with human insulin, saline infusion and insulin detemir. Despite cerebrocortical resistance to human insulin, insulin detemir increased beta activity in overweight human subjects, similar 
to human insulin in lean subjects. The authors suggest that the decreased cerebral beta-activity response in overweight subjects can be restored by insulin detemir. ${ }^{61}$

Hallschmid et $\mathrm{al}^{62}$ compared acute effects of human insulin and detemir on EEG measures and food intake in 15 healthy men during 2 hyperinsulinemic euglycemic clamps that included an insulin bolus injection (human insulin, detemir) followed by a steady 90 -minute infusion. Twenty minutes after infusion, subjects were allowed to eat ad libitum from a test buffet. While inducing comparable peripheral effects, detemir exerted stronger acute effects on brain functions than human insulin (it induced a negative DC-potential shift that was not observed during human insulin infusion) and triggered a relative decrease in food consumption - by $303 \mathrm{kcal}(P<0.04)$, suggesting an enhanced anorexigenic impact of detemir compared to human insulin on central nervous networks that control nutrient uptake.

\section{Safety and tolerability}

Beside influencing glucose metabolism, insulin exerts other biological functions such as proliferation, differentiation, and cell apoptosis. Insulin activity is driven through specific insulin receptors. At low concentrations its intercellular activity leads to a very quick appearance of metabolic effects. At higher concentrations insulin affects processes such as growth promotion by binding and stimulating insulin-like growth factor type I(IGF-I). ${ }^{63}$ The B26-B30 region of the insulin molecule has been critical for insulin receptor recognition, but the C-terminal end of the insulin B chain seems to be important in insulin binding to the IGF-I receptor. Multiple factors such as residence time on the receptor, dissociation rate, rate of receptor internalization and the degree of phosphorylation of signaling proteins can affect the mitogenic potencies of insulin analogs. ${ }^{64}$

Insulin analogs were developed to modify the structure of the human insulin molecule in order to more accurately approximate the endogenous secretion of insulin. Changing the structure of the insulin molecule, however, may significantly alter both its metabolic and mitogenic activity and have raised concerns about the safety of the insulin analogs. ${ }^{63}$

There is epidemiological evidence that diabetes is an independent predictor of cancer of the breast, colon, bladder, liver, pancreas and endometrium. However, clinical data on the relationship between risk of cancer and insulin treatment are sparse. IGF-I has been implicated as playing an important role in the progression and, potentially, in the development of human cancers. Epidemiological data have revealed that patients with high levels of IGF-I have an increased risk of developing cancer compared with those with IGF-I levels in the low and normal ranges. Last but not least, based on the expected role of IGF-I in tumor growth, anti-IGF-I receptor antibodies have been explored for the treatment of certain cancers. ${ }^{65}$

A mitogenic potential of insulin analogs (lispro, aspart, detemir and glargine) was studied by Kurtzhals et al ${ }^{66}$ using an experiment with human osteosarcoma cells. The rapid-acting insulin analogs aspart and lispro resembled human insulin in all parameters. In this experiment with human osteosarcoma cells, the long-acting basal analog detemir had decreased IGF-I receptor affinity and mitogenicity, but insulin glargine had increases in both of them. However, based on studies performed in vitro with different cell lines, the increased mitogenic potency was observed only in the studies with human osteosarcoma cells. ${ }^{63}$ A very recent metaanalysis of randomized, controlled basal insulin analog trials ${ }^{65}$ did not show any increased risk for having a cancer in patients treated with detemir, glargine and NPH insulin.

Wada et al $^{67}$ studied intracellular signaling properties of NPH, glargine and detemir insulins in various cultured cells and receptors. For the metabolic signaling, glargine and NPH insulin induced comparable dose-dependent phosphorylation of the studied receptors, whereas detemirinduced kinetics were markedly lower in adipocytes and myocytes. The authors concluded that their results indicate that glargine has comparable properties to human insulin in metabolic and mitogenic signaling and action. In contrast, detemir-induced metabolic signaling was less potent in all cell types studied, and it was reduced further by increasing concentrations of albumin.

Based on published clinical data from different studies which did not have sufficiently long-term duration and size, it is not possible to draw definite conclusions on the risk of cancer promotion by insulin analogs.

\section{Conclusions}

Insulin detemir is a basal insulin analog that provides an effective therapeutic option for patients with type 1 and type $2 \mathrm{DM}$, which is in agreement with recent guidelines. ${ }^{25}$ For glycemic control, no significant differences were found in $\mathrm{HbA}_{1 \mathrm{c}}$ levels when insulin detemir is compared with NPH insulin.

However, it has been demonstrated that insulin detemir is responsible for significantly lower within-subject variability than NPH insulin and insulin glargine. Detemir is comparable with insulin glargine in significantly reducing the rate of all types of hypoglycemia. But this insulin provides the more favorable clinical benefit of no or less weight gain than NPH 
insulin and glargine. Recent pharmacodynamic studies have shown that detemir can be used once daily in many patients with diabetes. Patients can be safely switched from one basal insulin to another, but close monitoring during transition is necessary as there may be dose differences with requirements for a higher dose of insulin detemir. ${ }^{68}$ Together with patient-friendly injection devices and dose adjustments, it provides a treatment option with the potential to lower the key barriers of adherence to insulin therapy in type $2 \mathrm{DM}$. Moreover, confusing results of an intensive treatment of hyperglycemia on cardiovascular outcomes in type $2 \mathrm{DM}$, which were recently discussed intensively, ${ }^{32}$ have independently suggested starting intensive therapy of hyperglycemia at an early stage of diabetes and to prefer those therapeutic options which provide the possibility to reach $\mathrm{HbA}_{1 \mathrm{c}}$ goals individually with a low risk of hypoglycemia or other adverse effects of treatment. The properties of insulin detemir correspond with these requirements.

\section{Disclosure}

The author discloses no conflicts of interest.

\section{References}

1. Balkau B, Eschwege E. The diagnosis and classification of diabetes mellitus and impaired glucose regulation. In Pickup JC, Williams G, editors. Textbook of Diabetes. Oxford: Blackwell Science;2003:2.1-2.13.

2. Karvonen M, Viik-Kajander M, Moltchanova E, Libman I, LaPorte R, Tuomilehto J. For the Diabetes mondiale (DiaMond). Incidence of Childhood Type 1 DiabetesWorldwide. Diabetes Care. 2000;23(10):1516-1526.

3. Variation and trends in incidence of childhood diabetes in Europe. EURODIAB ACE Study Group. Lancet. 2000;355(9207):873-876.

4. Kilpatrick ES, Rigby AS, Atkins SL. The Diabetes Control and Complications Trial: the gift that keeps giving. Nat Rev Endocrinol. 2009;5(10):537-545.

5. Swinnen SG, Hoekstra JB, DeVries JH. Insulin therapy for type 2 diabetes. Diabetes Care. 2009;32(Suppl 2):S253-S259.

6. Meneghini LF. Early insulin treatment in type 2 diabetes: what are the pros? Diabetes Care. 2009;32(Suppl 2):S270-S274.

7. Jehle PM, Micheler C, Jehle DR, Breitig D, Boehm BO. Inadequate suspension of neutral protamine Hagedorn (NPH) insulin in pens. Lancet. 1999;354(9190):1604-1607.

8. DeVries JH, Nattrass M, Pieber TR. Refining basal insulin therapy: what have we learned in the age of analogues? Diabetes Metab Res Rev. 2007;23(6):441-454.

9. Philips JC, Scheen A. Insulin detemir in the treatment of type 1 and 2 diabetes. Vasc Health Risk Manage. 2006;2(3):277-283.

10. Markussen J, Havelund S, Kurtzhals P, Andersen AS. Soluble, fatty acid acylated insulins bind to albumin and show protracted action in pigs. Diabetologia. 1996;39(3):281-288.

11. Lindholm A. 2002. New insulins in the treatment of diabetes mellitus. Best Pract Res Clin Gastroenterol. 2009;16(3):475-492.

12. Hermansen K, Madsbad S, Perrild H, Kristensen A, Axelsen M. Comparison of the soluble basal insulin analog insulin detemir with NPH insulin: a randomized open crossover trial in type 1 diabetic subjects on basal-bolus therapy. Diabetes Care. 2001;24(2): 296-301.
13. Heise T, Nosek L, Ronn BB, et al. Lower within-subject variability of insulin detemir in comparison to NPH insulin and insulin glargine in people with type 1 diabetes. Diabetes. 2004;53(6):1614-1620.

14. Danne T, Lüpke K, Walte K, Von Schuetz W, Gall MA. Insulin detemir is characterized by a consistent pharmacokinetic profile across age-groups in children, adolescents, and adults with type 1 diabetes. Diabetes Care. 2003;26(11):3087-3092.

15. Hompesch M, Troupin B, Heise T, et al. Time-action profile of insulin detemir and NPH insulin in patients with type 2diabetes from different ethnic groups. Diabetes Obes Metab. 2006;8(5):568-573.

16. Plank J, Bodenlenz M, Sinner F, et al. A double-blind, randomized, dose-response study investigating the pharmacodynamic and pharmacokinetic properties of the long-acting insulin analog detemir. Diabetes Care. 2005;28(5):1107-1112.

17. Porcellati F, Rosetti P, Ricci Busciantella N, et al. Comparison of pharmacokinetics and dynamics of the long-acting insulin analogs glargine and detemir at steady state in type 1 diabetes. Diabetes Care. 2007;30(10):2447-2452.

18. Klein O, Lynge J, Endahl L, Damholt B, Nosek L, Heise T. Albuminbound basal insulin analogues (insulin detemir and NN344): comparable time - action profiles but less variability than insulin glargine in type 2 diabetes. Diabetes Obes Metab. 2007;9(3):290-299.

19. King AB. Once-dauly insulin detemir is comparable to once-dauly insulin glargine in providing glycaemic control over $24 \mathrm{~h}$ in patients with type 2 diabetes: a double-blind, randomized, crossover study. Diabetes Obes Metab. 2009;11(1):69-71.

20. Tschritter O, Schäfer SA, Klett J, et al. Insulin detemir causes increased symptom awareness during hypoglycaemia compared to human insulin. Diabetes Obes Metab. 2009;11(11):1017-1026.

21. Torlone E, DiCianni G, Mannino D, Lapolla A. Insulin analogs and pregnancy: an update. Acta Diabetol. 2009;46(3):163-172.

22. Singh SR, Ahmad F, Lal A, Yu C, Bai Z, Bennett H. Efficacy and safety of insulin analogues for the management of diabetes mellitus: a meta-analysis. CMAJ. 2009;180(4):385-397.

23. Pieber TR, Treichel HC, Hompesch B, et al. Comparison of insulin detemir and insulin glargine in subjects with Type 1 diabetes using intensive insulin therapy. Diabet Med. 2007;24(6):635-642.

24. Robertson KJ, Schoenle E, Gucev Z, Mordhorst L, Gall MA, Ludviqsson J. Insulin detemir compared with NPH insulin in children and adolescents with Type 1 diabetes. Diabet Med. 2007;24(1):27-34.

25. Klein O, Lynge J, Endahl L, Damholt B,Nosek L, Heise T. Albuminbound basal insulin analogues (insulin detemir and NN344): comparable time-action profiles but less variability than insulin glargine in type 2 diabetes. Diabetes Obes Metab. 2007;9(3):290-299.

26. Le Floch JP, Lévy M, Mosnier-Pudar H, et al. Assessment of Detemir Administration in Progressive Treat-to-Target Trial (ADAPT) Study Group. Comparison of once- versus twice-daily administration of insulin detemir, used with mealtime insulin aspart, in basal-bolus therapy for type 1 diabetes: assessment of detemir administration in a progressive treat-to-target trial (ADAPT). Diabetes Care. 2009;32(1): 32-37.

27. Heller S, Koenen C, Bode B. Comparison of insulin detemir and insulin glargine in a basal-bolus regimen, with insulin aspart as the mealtime insulin, in patients with type 1 diabetes: a 52-week, multinational, randomized, open-label, parallel-group, treat-to-target noninferiority trial. Clin Ther. 2009;31(10):2086-2097.

28. Bartley PC, Bogoev M, Larsen J, Philotheou A. Long-term efficacy and safety of insulin detemir compared to Neutral Protamine Hagedorn insulin in patients with Type 1 diabetes using a treat-to-target basal-bolus regimen with insulin aspart at meals: a 2-year, randomized, controlled trial. Diabet Med. 2008;25(4):442-449.

29. Dornhorst A, Lüddeke HJ, Honka M, et al. PREDICTIVE Study Group. Safety and efficacy of insulin detemir basal-bolus therapy in type 1 diabetes patients: 14-week data from the European cohort of the PREDICTIVE study. Curr Med Res Opin. 2008; 24(2):369-376. 
30. Nathan DM, Buse JB, Davidson MB, et al. Medical management of hyperglycemia in type 2 diabetes: a consensus algorithm for the initiation and adjustment of therapy: a consensus statement of the American Diabetes Association and the European Association for the Study of Diabetes. Diabetes Care. 2009;32(1):193-203.

31. Horvath K, Jeitler K, Berghold A, et al. Long-acting insulin analogues versus NPH insulin (human isophane insulin) for type 2 diabetes mellitus. Cochrane Database Syst Rev. 2007;Apr 18;(2): CD005613.

32. Ray KK, Wilde MI, Sivakumaran R, et al. Effect of intensive control of glucose on cardiovascular outcomes and death in patients with diabetes mellitus: a meta-analysis of randomised controlled trials. Lancet. 2009;373(9677):1765-1772.

33. Rodbard HW, Jellinger PS, Davidson JA, et al. Statement by an American Association of Clinical Endocrinologists/American College of Endocrinology. Consensus Panel on Type 2 Diabetes Mellitus: an algorithm for glycemic control. Endocr Pract. 2009;15(6):540-559. Erratum in: Endocr Pract. 2009;15(7):768-770.

34. Raslova K, Bogoev M, Raz I, Leth G, Gall MA, Hâncu N. Insulin detemir and insulin aspart: a promising basal-bolus regimen for type 2 diabetes. Diabetes Res Clin Pract. 2004;66(2):193-201. Corrigendum in: Diabetes Res Clin Pract. 2006;72(1):112.

35. Haak T, Tiengo A, Draeger E, Suntum M, Waldhäusl W. Lower withinsubject variability of fasting blood glucose and reduced weight gain with insulin detemir compared to NPH insulin in patients with type 2 diabetes. Diabetes Obes Metab. 2005;7(1):56-64.

36. Hermansen K, Davies M, Derezinski T, Martinez Ravn G, Clauson P, Home P. A 26-week, randomized, parallel, treat-to-target trial comparing insulin detemir with NPH insulin as add-on therapy to oral glucoselowering drugs in insulin-naive people with type 2 diabetes. Diabetes Care. 2006;29(6):1269-1274.

37. Philis-Tsimikas A, Charpentier G, Clauson P, Ravn GM, Roberts VL, Thorsteinsson B. Comparison of once-daily insulin detemir with NPH insulin added to a regimen of oral antidiabetic drugs in poorly controlled type 2 diabetes. Clin Ther. 2006;28(10):1569-1581.

38. Liebl A, Prager R, Binz K, Kaiser M, Bergenstal R, Gallwitz B. PREFER Study Group. Comparison of insulin analogue regimens in people with type 2 diabetes mellitus in the PREFER Study: a randomized controlled trial. Diabetes Obes Metab. 2009;11(1):45-52.

39. Hollander P, Cooper J, Bregnhøj J, Pedersen CB. A 52-week, multinational, open-label, parallel-group, noninferiority, treat-to-target trial comparing insulin detemir with insulin glargine in a basal-bolus regimen with mealtime insulin aspart in patients with type 2 diabetes. Clin Ther. 2008;30(11):1976-1987.

40. Rosenstock J, Davies M, Home PD, Larsen J, Koenen C, Schernthaner G. A randomised, 52-week, treat-to-target trial comparing insulin detemir with insulin glargine when administered as add-on to glucose-lowering drugs in insulin-naive people with type 2 diabetes. Diabetologia. 2008;51(3):408-416.

41. Raskin P, Gylvin T, Weng W, Chaykin L. Comparison of insulin detemir and insulin glargine using a basal-bolus regimen in a randomized, controlled clinical study in patients with type 2 diabetes. Diabetes Metab Res Rev. 2009;25(6):542-548

42. Swinnen SG, Dain MP, Aronson R, et al. A 24-week, randomized, treatto-target trial comparing initiation of insulin glargine once-daily with insulin detemir twice-daily in patients with type 2 diabetes inadequately controlled on oral glucose-lowering drugs. Diabetes Care. 2010 Mar 3. [Epub ahead of print].

43. Holman RR, Farmer AJ, Davies MJ, et al. 4-T Study Group. Three-year efficacy of complex insulin regimens in type 2 diabetes. $N$ Engl J Med. 2009;361(18):1736-1747.

44. Dornhorst A, Lüddeke HJ, Honka M, et al. PREDICTIVE Study Group. Safety and efficacy of insulin detemir basal-bolus therapy in type 1 diabetes patients: 14-week data from the European cohort of the PREDICTIVE study. Curr Med Res Opin. 2008;24(2): 369-376.
45. Meneghini LF, Dornhorst A, Sreenan S;PREDICTIVE Study Group. Once-daily insulin detemir in a cohort of insulin-naïve patients with type 2 diabetes: a sub-analysis from the PREDICTIVE study. Curr Med Res Opin. 2009;25(4):1029-1035.

46. Stratton IM, Adler AI, Neil HA, et al. Association of glycaemia with macrovascular and microvascular complications of type 2 diabetes (UKPDS 35): prospective observational study. BMJ. 2000;321(7258): 405-412.

47. Purnell JQ, Hokanson JE, Marcovina SM, Steffes MW, Cleary PA, Brunzell JD. Effect of excessive weight gain with intensive therapy of type 1 diabetes on lipid levels and blood pressure: results from the DCCT. Diabetes Control and Complications Trial. JAMA. 1998;280(2): $140-146$.

48. Yki-Jarvinen H, Ryysy L, Kauppila M, et al. Effect of obesity on the response to insulin therapy in noninsulin-dependent diabetes mellitus. J Clin Endocrinol Metab. 1997;82(12):4037-4043.

49. Pieber TR, Draeger E, Kristensen A, Grill V. Comparison of three multiple injection regimens for Type 1 diabetes: morning plus dinner or bedtime administration of insulin detemir vs morning plus bedtime NPH insulin. Diabet Med. 2005;22(7):850-8577.

50. De Leeuw I, Vague P, Selam JL, et al. Insulin detemir used in basalbolus therapy in people with type 1 diabetes is associated with a lower risk of nocturnal hypoglycaemia and less weight gain over 12 months in comparison to NPH insulin. Diabetes Obes Metab. 2005;7(1): 73-82.

51. Hermansen K, Fontaine P, Kukolja KK, Peterkova V, Leth G, Gall MA. Insulin analogues (insulin detemir and insulin aspart) versus traditional human insulins (NPH insulin and regular human insulin) in basal-bolus therapy for patients with type 1 diabetes. Diabetologia. 2004;47(4):622-629.

52. Home P, Bartley P, Russell-Jones D, et al. Study to Evaluate the Administration of Detemir Insulin Efficacy, Safety and Suitability (STEADINESS) Study Group. Insulin detemir offers improved glycemic control compared with NPH insulin in people with type 1 diabetes: a randomized clinical trial. Diabetes Care. 2004;27(5):1081-1087.

53. Russell-Jones D, Simpson R, Hylleberg B, Draeger E, Bolinder J. Effects of QD insulin detemir or neutral protamine Hagedorn on blood glucose control in patients with type I diabetes mellitus using a basal-bolus regimen. Clin Ther. 2004;26(5):724-736.

54. Standl E, Lang H, Roberts A. The 12-month efficacy and safety of insulin detemir and NPH insulin in basal-bolus therapy for the treatment of type 1 diabetes. Diabetes Technol Ther. 2004;6(5):579-588.

55. Vague P, Selam JL, Skeie S, et al. Insulin detemir is associated with more predictable glycemic control and reduced risk of hypoglycemia than NPH insulin in patients with type 1 diabetes on a basal-bolus regimen with premeal insulin aspart. Diabetes Care. 2003;26(3): 590-596.

56. Raslova K, Tamer SC, Clauson P, Karl D. Insulin detemir results in less weight gain than NPH insulin when used in basal-bolus therapy for type 2 diabetes mellitus, and this advantage increases with baseline body mass index. Clin Drug Invest. 2007;27(4):279-285.

57. Demssie YN, Younis N, Soran H. The role of insulin detemir in overweight type 2 diabetes management. Vasc Health Risk Manag 2009;5(3):553-560.

58. Davies M, Khunti K. Insulin management in overweight or obese type 2 diabetes patients: the role of insulin glargine. Diabetes Obes Metab. 2008;10 Suppl 2:S42-S49.

59. Davies MJ, Derezinski T, Pedersen CB, Clauson P. Reduced weight gain with insulin detemir compared to NPH insulin is not explained by a reduction in hypoglycemia. Diabetes Technol Ther. 2008;10(4): 273-277.

60. Hermansen K, Davies M. Does insulin detemir have a role in reducing risk of insulin-associated weight gain? Diabetes Obes Metab. 2007;9(3):209-217.

61. Tschritter O, Hennige AM, Preissl H, et al. Cerebrocortical beta activity in overweight humans responds to insulin detemir. PLoS One. 2007;2(11):e1196 
62. Hallschmid M, Jauch-Chara K, Korn O, et al. Euglycemic infusion of insulin detemir compared to human insulin appears to increase direct current brain potential response and reduces food intake while inducing similar systemic effects. Diabetes. 2010. Jan 12. [Epub ahead of print].

63. Żełobowska K, Gumprecht J, Grzeszczak W. Mitogenic potency of insulin glargine Pol J Endocrinol. 2009;60(1):34-39.

64. Zib I, Raskin P. Novel insulin analogues and its mitogenic potential. Diabetes Obes Metab. 2006;8(6):611-620.

65. Dejgaard A, Lynggaard H, Råstam J, Krogsgaard Thomsen M. No evidence of increased risk of malignancies in patients with diabetes treated with insulin detemir: a meta-analysis. Diabetologia. 2009; 52(12):2507-2512.
66. Kurtzhals P, Schäffer L, Sorensen A, et al. Correlations of receptor binding and metabolic and mitogenic potencies of insulin analogs designed for clinical use. Diabetes. 2000;49(6):999-1005.

67. Wada T, Azegami M, Sugiyama M, Tsuneki H, Sasaoka T. Characteristics of signaling properties mediated by long-acting insulin analogue glargine and detemir in target cells of insulin. Diabetes Res Clin Pract. 2008;81(3):269-277.

68. Reynolds LR. Comparing insulins detemir and glargine in type 2 diabetes: more similarities than differences. Commentary. Postgrad Med. 2010;122(1):201-203.

\section{Publish your work in this journal}

Vascular Health and Risk Management is an international, peerreviewed journal of therapeutics and risk management, focusing on concise rapid reporting of clinical studies on the processes involved in the maintenance of vascular health; the monitoring, prevention and treatment of vascular disease and its sequelae; and the involvement of metabolic disorders, particularly diabetes. This journal is indexed on PubMed Central and MedLine. The manuscript management system is completely online and includes a very quick and fair peer-review system, which is all easy to use. Visit http://www.dovepress.com/ testimonials.php to read real quotes from published authors. 